\title{
POLÍTICAS DA MEMÓRIA E DO ESQUECIMENTO: O PATRIMÔNIO DO PORTO DE SÃO LOURENÇO DO SUL/RS E A SUA IMPORTÂNCIA NA CONSTITUIÇÃO DA CIDADE.
}

\section{Samila Pereira Ferreira*}

* Professora assistente no Centro de Investigaciones del Patrimonio Costero (CIPAC), Centro

Universitario de la Región Este (CURE), Universidad de la República (UdelaR).
RESUMO: A história da cidade de São Lourenço do Sul vem sendo contada sob a ótica de sua formação através dos imigrantes alemãespomeranos, esquecendo a coexistência de outras atividades como as mercantis realizadas através dos lates que abasteciam o porto local. A memória, matéria-prima da História, seleciona a partir dos anseios individuais e coletivos do presente os fatos que devem e podem ser lembrados e/ou esquecidos, dentro de um campo de disputas de poder. Desta forma, a memória de alguns grupos da cidade, que de alguma forma estão vinculadas a um passado mercantil e náutico, tem sido negligenciada neste campo de disputas. Observando a cidade, em sua materialidade e na própria vida social atual, é possível identificar traços ainda ativos desses homens que, através de seu trabalho, constituíram parte de seu patrimônio. Neste sentido, buscamos na paisagem cultural e nos vestígios remanescentes a história de grupos sociais esquecidos e que foram ativos na construção da cidade. Ao lado da aplicação dos métodos e do debate crescente vinculado ao estudo da memória e do patrimônio nas sociedades contemporâneas, utilizaremos também o método da história oral. Através da materialidade da cultura e dos relatos de pessoas que vivenciaram essa época busquei perceber as relações sociais e o cotidiano do trabalho.

Palavras-chave: paisagem cultural, políticas públicas, lates, São Lourenço do Sul.

ABSTRACT: The history of São Lourenço do Sulcity has been toldfrom the point of view of the the German-Pomeranian immigrants, forgetting the coexistence of other activities like the shippingcarried through the yachts which had supplied the local port. Memory, the raw material of history, selects from the individual and collective yearnings of the present the facts that must and can be remembered and/or forgotten, because both are constructions that occur in a field of power disputes. In this way, the memory of some groups of the city that, somehow, are linked to a mercantile and nautical past, has been neglected in this field of disputes. Observing the city, in its materiality and in the current social life itself, it is possible to identify active traits of these men who, throughout their work, constituted part of the city. In this sense, we seek in the cultural landscape and in the remnants vestiges, the history of social groups forgotten, and that were active in the construction of the city. Alongside the application of methods and the growing debate linked to the study of memory and heritage in contemporary societies, we have also used the method of oral history. Through the materiality of culture and the reports of people who lived through this time, I sought to perceive social and work relations.

Keywords: cultural landscape, publicpolicy, Yachts, São Lourenço do Sul. 


\section{Introdução}

As casas, as ruas, o rio, os prédios e as imagens, acrescidos das lembranças das pessoas que vivenciaram uma determinada época, multiplicam os significados e suas histórias. Inúmeras lembranças são evocadas com uma simples imagem. Através das feições e dos traços marcados pelo tempo, identificamos quantas foram as formas de um prédio, assim como suas cores e funções.

Os gestos das mãos apontam a rua e o vai-e-vem de pessoas, e por um descuido de atenção é possível enxergar o movimento. $O$ rio é a força viva de uma cidade. Ele condiciona, distribui e organiza uma pequena sociedade que em sua ribeira pretende se fixar e progredir junto a ele. Os barcos que pelo rio navegam são abarrotados de mercadorias que abastecem cidades próximas e a própria cidade. Carregam produtos, pessoas e histórias. Carregam perigos e intempéries, assim como calmarias e a bonança. Carregam mastros e velas que se interligam com as mãos daqueles que reparam embarcações.

Basta fixar rapidamente os olhos em uma fotografia para as lembranças fervilharem. Com a fotografia em mãos e o olhar focando o nada, parece que o instante daquela imagem carrega consigo muitas pessoas, lugares e histórias que não aparecem no papel retangular. A nostalgia refletida no discurso, no silêncio, no olhar é perceptível e é compreendida pela falta de reconhecimento, pelo abandono, pelo esquecimento.

Com essa descrição se poderia estar falando de inúmeras cidades brasileiras que durante os séculos XIX e XX constituíram-se através das práticas portuárias e que, a partir de transformações sócio-econômicas advindas da modernização dos transportes, foram sucumbindo gradativamente, obliteradas do contexto econômico da época e, em alguns lugares, do contexto cultural.

Nessa pesquisa busquei recuperar elementos que evidenciassem a importância da zona portuária na cidade de São Lourenço, marcadamente excluída do discurso patrimonial veiculado pelas políticas públicas. Para tanto, a metodologia utilizada baseou-se na revisão bibliográfica, no registro dos vestígios materiais remanescentes do espaço urbano-portuário estudado, na análise de fotografias antigas, mapas e relatos de história.

O objeto desta pesquisa foi a região portuária da cidade de São Lourenço do Sul, Rio Grande do Sul, visto como um espaço cuja vitalidade não está mais evidenciada, mas que foi de fundamental importância para a formação desse lugar. O contexto histórico desta pesquisa compreende o período de formação sócio-histórica da cidade que se estende desde o final do século XIX (1884), até o período de decadência e ocaso da atividade comercial dos lates, em meados do século XX(1960). A problemática em estudo, entretanto, se localiza nos processos contemporâneos de construção da memória. 


\section{O contexto histórico da cidade e da empresa de colonização}

O Rio Grande do Sul ou Província do Rio Grande de São Pedro, durante o século XIX, se constituiu pelo predomínio da pecuária extensiva, pouca necessidade de mão-de-obra e de grandes propriedades, bases do desenvolvimento de sua economia. A pecuária sempre esteve associada ao desenvolvimento da região sul no período do Brasil Colonial e posteriormente no Império, diferenciando-se das demais províncias como Minas Gerais, Rio de Janeiro e São Paulo que dependiam em grande parte da demanda internacional.

A história da cidade de São Lourenço do Sul remonta ao início do século XIX, onde já se encontram registros do "Distrito de São Lourenço da Vila do Rio Grande de São Pedro". Os primeiros registros de casamentos no oratório de São Lourenço localizado na estância de mesmo nome, onde havia atividades de plantação, charqueada e porto, são datados de 1800 (Caldas, 2009). A reconstrução da história da cidade através dos vestígios materiais e do levantamento documental ainda necessita ser melhor e mais amplamente trabalhada.

Algumas informações e hipóteses são apontadas sem, no entanto, referências de fontes, o que prejudica o trabalho de investigação do pesquisador. A primeira ocupação conhecida, nas terras da atual São Lourenço do Sul, é onde se localizaria a propriedade do Alferes português Joaquim Gonçalves da Silva, criador de gado e também proprietário das terras onde é atualmente a região de Camaquã, na margem direita da Lagoa dos Patos (Spalding, 1974).

No intuito de expandir os negócios de criação de gado e demarcar a posse de sua propriedade, Joaquim Gonçalves realiza o casamento de sua filha Anna Joaquina Gonçalves da Silva com José da Costa Santos, residente na cidade do Rio Grande/RS, aliança essa que dá início a construção de um imponente sobrado, na margem esquerda do rio São Lourenço. $O$ início da construção data aproximadamente de finais do século XVIII (Abreu, 2001).

Neste contexto, surge a presença de José Antônio de Oliveira Guimarães que, através do casamento com sua prima, passa a ser proprietário das terras onde posteriormente viria a ser São Lourenço do Sul (Idem.). José Antônio de Oliveira Guimarães possuía a patente de capitão e recebendo sugestões do amigo Domingos José de Almeida, vereador do Partido Liberal em Pelotas/RS e ex-ministro Farroupilha, estabeleceu um plano estratégico de desenvolvimento para São Lourenço do Sul. Os principais objetivos eram: a construção de uma estrada ligando a cidade de Canguçu ao porto de São Lourenço, a criação de um povoado junto àquele porto e a implantação de uma colônia de imigrantes europeus entre as atuais localidades de Boqueirão e Quevedos, situadas a aproximadamente 12 km de São Lourenço do Sul (Caldas, 2009).

Quando o Partido Liberal dominou a Assembléia Provincial gaúcha, Guimarães e Almeida conseguiram a primeira vitória: a aprovação de verba para a estrada, trecho BoqueirãoQuevedos, que foi concluída em 1859. No ano anterior, a empresa fundada por Guimarães e Jacob Rheingantz dera início à colonização de imigrantes europeus no sul do Brasil. Em 1860, Guimarães elegeu-se vereador e logo entrou com a proposta para que a sede da freguesia fosse mudada de Boqueirão para São Lourenço, o que foi aprovado pela Assembléia Provincial em 1861. “Enquanto o Boqueirão do tempo das carretas e tropas de gado estagnara, em São Lourenço circulava o dinheiro, crescia o comércio de produtos agrícolas, o tráfego de 
embarcações. Aliás, este argumento foi utilizado pelo deputado liberal Saturnino Arruda ao defender a lei que aprovou, em 29 de abril de 1876, a criação da freguesia de São Lourenço" (Caldas, 2009: 2).

Assim, no ano de 1858 aparece a figura de Jacob Rheingantz, comerciante da região do vale do Rio Reno na Alemanha, que estabelece uma empresa de colonização na Serra dos Tapes juntamente com seu sócio José Antônio de Oliveira Guimarães. A sociedade perdurou durante os cinco primeiros anos da empresa de colonização (lepsen, 2008: 102) e com esse processo migratório povoou-se a região do porto onde primeiramente estava situada planta urbana da cidade.

Essas terras pertenciam na época ao município de Pelotas e eram adequadas para o cultivo e comercialização de produtos agrícolas com mão-de-obra livre trazida da Europa. Inicialmente esta colônia atingiu relevante sucesso diante de outras colônias estabelecidas no sul do Brasil (frequentemente dependentes do auxílio de Portugal) devido ao fato do empreendedor Jacob Rheingantz, antes de dar início ao seu projeto, já estar estabelecido no sul do Brasil, residindo primeiramente na cidade de Rio Grande e após em Pelotas (Coaracy, 1957: 38).

Diferentemente das demais regiões do país, a imigração européia no RS não aconteceu no intuito de substituir a mão-de-obra escrava das atividades charqueadoras e sim de criar uma nova relação de propriedade e trabalho garantindo o domínio no Império sobre o território. Nesse sentido a imigração propõe uma solução para o governo, não para os charqueadores, situação que difere do caso dos cafeicultores paulistas (Saviani Filho, 2008).

Mesmo que a oligarquia do charque não tivesse o mesmo prestígio e poder das oligarquias centrais de São Paulo e do Rio de Janeiro, e não conseguindo barrar o projeto de colonização do estado, conseguiram-se concessões sobre o local de instalação das futuras colônias, que não poderiam estar em áreas de interesses da pecuária. Sendo assim, as terras disponíveis para a colonização eram as regiões inóspitas de florestas e de montanhas (Id. Ib.).

Além disso, a colonização servira de resposta às pressões inglesas sobre a abolição da escravatura que estavam sujeitas ao governo imperial e o estabelecimento de fronteiras. Outro ponto que vale destaque é que, ainda no século XIX, a população do Rio Grande do Sul não ultrapassava os 450 mil habitantes numa extensão de $283 \mathrm{mil} \mathrm{km}^{2}$ (Saviani Filho, 2008: 161). Nesse sentido, a falta de mão-de-obra era motivo de inquietação do governo imperial, o que levou D. Pedro I a optar pelo estímulo a vinda de imigrantes (Id. Ib.).

No sul do RS, mais precisamente onde se localiza atualmente a cidade de São Lourenço do Sul, esse ingresso de mão de obra de origem européia se deu através do fazendeiro José Antônio de Oliveira Guimarães, proprietário das terras situadas à margem esquerda do rio São Lourenço, e do imigrante renano Jacob Rheingantz. Sobre Jacob Rheingantz sabe-se que era natural de Sponheim, região da Prússia Rhenana (estado alemão), nascido no ano de 1817 e desde jovem passou a desempenhar atividades em uma casa de vinhos na região de Kreuznach. Em 1839 migrou para a França a fim de trabalhar em uma casa de vinhos da região de Champagne (lepsen, 2008: 23). 
Após sua estada na França, Jacob Rheingantz decide migrar para os Estados Unidos a fim de trabalhar com seu irmão. Não obtendo sucesso na empreitada, em detrimento do falecimento do irmão e não atingir seu objetivo econômico, Rheingantz opta por migrar para o Brasil e no ano de 1843 desembarca no porto da cidade de Rio Grande. Nessa cidade, tal como aponta lepsen (2008), foi trabalhar em casas comerciais e no setor de exportação, tornando-se rapidamente num dos comerciantes mais fortes do lugar.

No ano de 1854 é promulgada a Lei Provincial $n^{\circ} 304$ que proibia a doação de lotes de terras aos imigrantes e instaurou que a concessão das terras seria liberada através da venda. Sendo assim, após adquirir capital, Rheingantz idealizou uma colônia de imigrantes europeus na Serra dos Tapes, região de São Lourenço do Sul.

Sendo assim, no ano de 1856, Rheingantz assina um contrato de colonização com o Império o qual Ihe vendia oito léguas de terras devolutas na Serra dos Tapes. No entanto, os custos da empreitada eram elevados e requeriam que Rheingantz encontrasse um sócio para dar continuidade ao projeto. Mesmo com o reconhecimento que tinha nas cidades de Rio Grande e Pelotas, foi em São Lourenço que realizou a parceria com José Antônio de Oliveira Guimarães e no ano de 1857 assinaram o contrato de sociedade válido por cinco anos, para efetivarem o projeto de colonização européia em São Lourenço (lepsen, 2008).

\section{Os lates e o contexto marítimo-mercantil da Lagoa dos Patos}

Situada na desembocadura do rio São Lourenço, na margem oeste da Lagoa dos Patos, a cidade de São Lourenço do Sul foi se constituindo durante o século XIX compassada pela atividade dos imigrantes e pelo movimento dos barcos que escoavam a produção da colônia, integrando a cidade às linhas de navegação e comércio da Lagoa dos Patos (Mapa 1).

Mapa 1: Localização da cidade de São Lourenço do Sul. Fonte: modificado do site do Ministério do Trabalho.

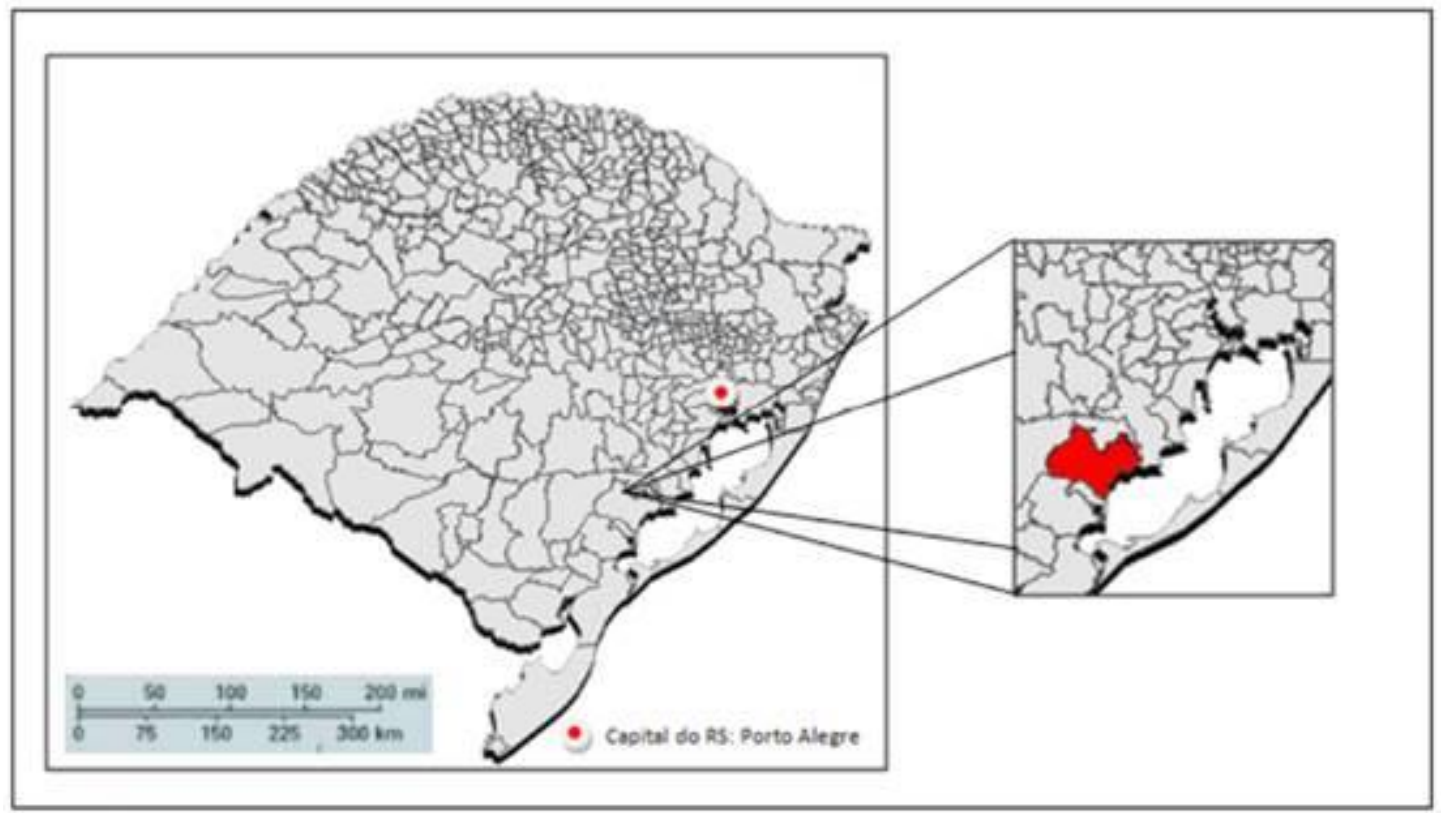


No que se refere a estrutura da economia colonial, de acordo com Saviani Filho (2008), o movimento migratório iniciado em 1824 diferenciou a região meridional do país em relação às demais províncias brasileiras. Essas áreas coloniais dinamizaram a economia sul-riograndense, pois alguns produtos agrícolas deixaram de ser importados e começaram a ser produzidos localmente. Os produtos vindos da colônia eram levados por meio de transporte de tração animal até as casas comerciais estabelecidas à margem do rio, junto à vila. Nestas casas e em seus armazéns as mercadorias eram estocadas e comercializadas, sendo redistribuídas para os demais portos da hidrovia Patos-Mirim por meio de embarcações conhecidas regionalmente como "lates" (Figura 1).

Figura 1: Típico late da Lagoa dos Patos. S/d. Acervo Digital do Museu Náutico/Furg.

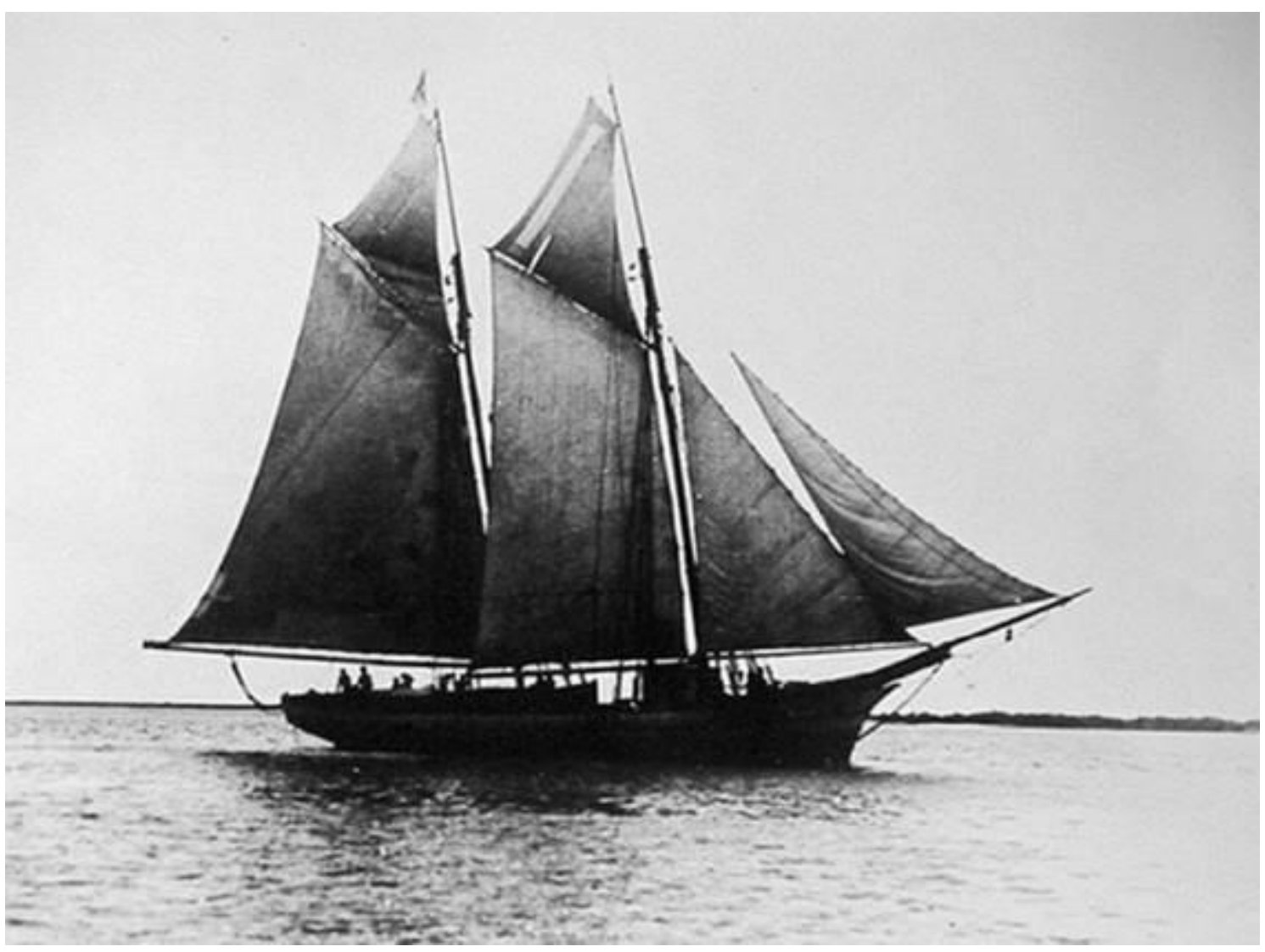

Os lates eram embarcações com capacidade de carga entre 20 e 120 toneladas, de 40 e 60 pés de comprimento, armação e velame de escuna ${ }^{1}$. Sua carga compunha-se tipicamente dos gêneros diversos consumidos na região: charque, grãos, farinha, aguardente, móveis, couro e madeira. A tripulação era distribuída em: mestre (posteriormente com a introdução do motor passou a ser o motorista), marinheiro (poderia ser um ou mais dependendo da carga e da necessidade), moço de convés (aprendiz) e cozinheiro (Copstein, 1992: 81-87).

1 "Armação" e "velame" são termos utilizados respectivamente para a mastreação e para o conjunto de velas de uma embarcação. Uma Escuna típica do século XIX possuía dois mastros, cujas velas denominavam-se: bujarrona, vela de estais, traquete, vela grande, gafitope. As embarcações denominadas regionalmente de lates podiam ter um ou dois mastros, sendo as de um mastro também chamadas de Cúters. 
Sobre o tema da atividade comercial e formação da zona portuária venho me dedicando desde 2007. O massivo discurso da cidade sobre sua história, festejos, rememorações, os lugares abandonados e as histórias que ouvia me causavam certo estranhamento ${ }^{2}$. Percebe-se que há exclusões importantes no discurso quase ufanista da colonização em São Lourenço e uma dessas exclusões é a importância do comércio vinculado ao rio, cujos vestígios materiais ainda se encontram na região.

Desde 2005, políticas ${ }^{3}$ públicas foram formuladas pela gestão municipal no intuito de revigorar a autoestima dos cidadãos lourencianos, principalmente os da zona rural, buscando parcerias público-privadas, fornecendo alternativas de trabalho e renda atreladas a história da imigração, folclore, cultura e gastronomia e visando desenvolver o turismo na cidade.

Por outro lado, elementos pertinentes, que também remontam à história do município, juntamente com as ruínas remanescentes do período estudado, pessoas que com seu trabalho exerceram as mais variadas atividades e que contribuíram na multiplicidade sócio-histórica da cidade, foram relegadas destas ações políticas de salvaguarda do que foi determinado como patrimônio de São Lourenço do Sul.

Neste trabalho, questiono o motivo que levou as medidas políticas e econômicas a partir de 2005 a se entrelaçar de tal forma com a cidade que gerou uma generalização da história focada somente sob o viés da colonização, remetendo e dedicando tal acontecimento a apenas um fundador, Jacob Rheigantz, e um momento histórico, a colonização. Nesse sentido, questiono também as eleições patrimoniais que estão sendo feitas e as políticas públicas formuladas para salvaguardar elementos culturais referentes ao fato da chegada dos imigrantes alemães-pomeranos ${ }^{4}$, esquecendo, sobretudo, outros elementos do processo de formação sócio-histórica da região, em particular, a atividade dos lates e dos navegadores.

As casas comerciais, das quais hoje pouco se encontra, foram originadas no contexto de uma economia baseada na agricultura e localizadas à ribeira do rio São Lourenço onde encontraram maior facilidade de escoamento dessa produção. Essas casas de comércio compravam, revendiam e exportavam produtos vindos da colônia.

Foram arroladas cinco casas de comércio situadas na beira do rio São Lourenço. Sabe-se que existiram muitas outras, mas para este trabalho optei por evidenciar as que foram mais citadas pelos entrevistados e aquelas que foram encontradas nas fotografias da cidade e na bibliografia consultada. Optamos também pelas casas situadas a beira-rio por ser o espaço privilegiado neste trabalho e porque alguns vestígios materiais ainda permanecem no local.

\footnotetext{
2 No sentido da Antropologia: "Disso decorre a necessidade, na formação antropológica, daquilo que não hesitarei em chamar de "estranhamento" (depaysement), a perplexidade provocada pelo encontro das culturas que são para nós as mais distantes, e cujo encontro vai levar a uma modificação de olhar que se tinha sobre si mesmo (Laplantine: 1991: 21).

3 "O termo político, polissêmico, não é visto, aqui, na sua abrangência, como restrito a uma ação que envolve "voto, partido, eleição". Pensa-se no que, em inglês se denomina "policy", ou seja, um sistema ou plano de ação" (Piccolo: 2005:1).

4 A rigor, só podemos falar de "alemães" após 1870, com o processo de unificação da Alemanha. No período da imigração, a "Alemanha" não existia. O território era divido em unidades nacionais independentes entre si, cada um com seu próprio dialeto.
} 
Políticas da Memória e do Esquecimento: O Patrimônio do Porto de São Lourenço do Sul/RS e a sua Importância na Constituição da Cidade.

As casas de comércio contempladas neste estudo são: Helms, João Duarte, Kath, Nickhorn e Timm(Mapa 2). Estes estabelecimentos comerciais trabalhavam basicamente com os produtos advindos da colônia de São Lourenço com exceção da casa Helms e Nickhorn que além dos produtos coloniais, trabalhavam com maior variedade de mercadorias. Entre eles, destacam-se a venda de tecidos, móveis, louças, secos e molhados, ferragem, madeira e etc.

Mapa 2: Localização de algumas casas comerciais. Fonte: modificado do Google Earth ${ }^{\circledR}$.

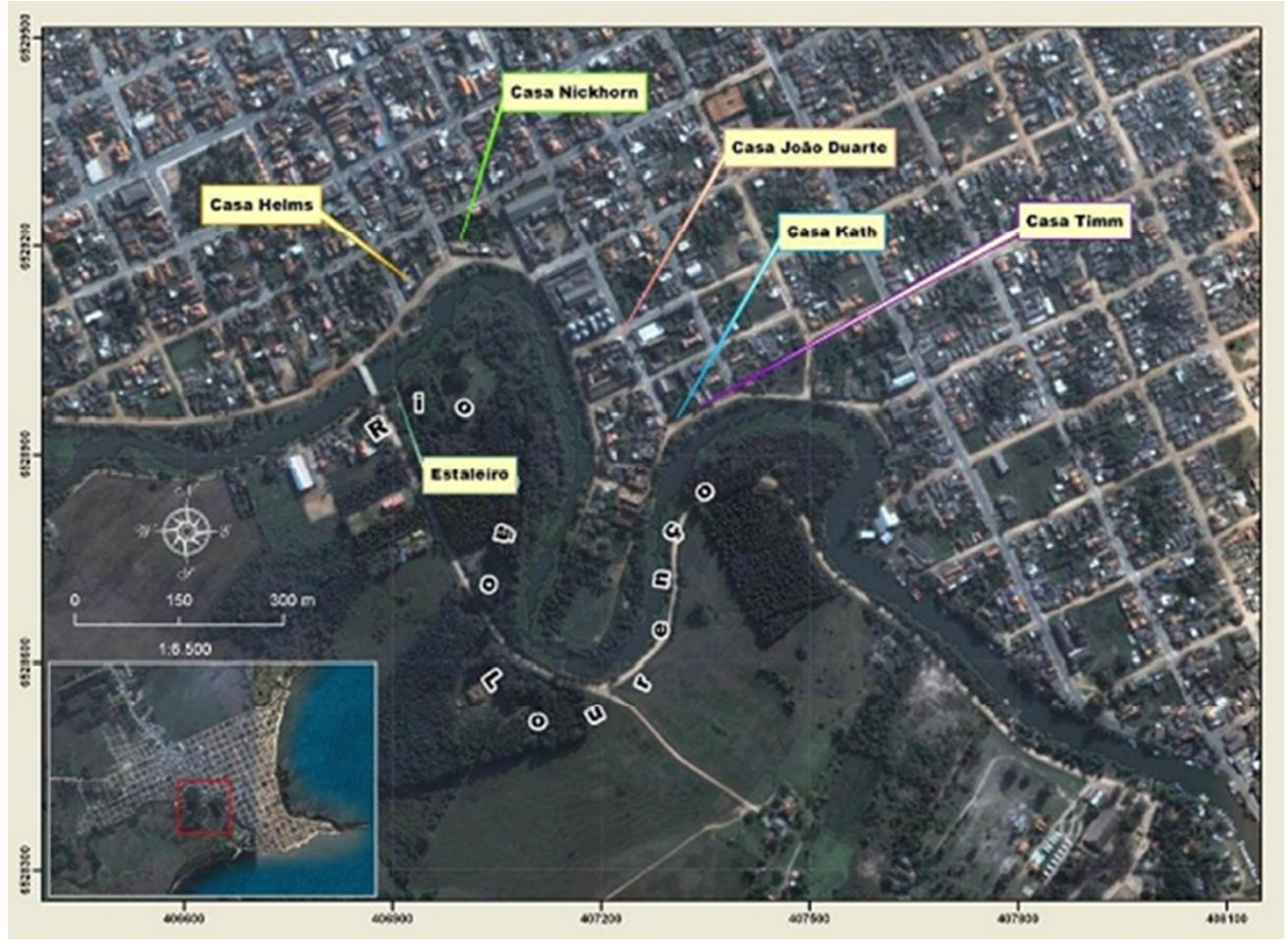

Todas as casas mencionadas possuíam seus próprios lates que permaneciam atracados em frente a seus prédios a fim de escoar o excedente de produtos comprados pelos comerciantes para serem revendidos na cidade de Rio Grande. Normalmente estas casas tinham sua própria tripulação e em casos esporádicos, de muita demanda, chegavam a fretar lates de outros proprietários.Os lates também faziam o caminho inverso e traziam mercadorias para serem revendidas na cidade. Os lates que navegavam no sistema de cabotagem também atracavam no porto de São Lourenço para realizarem negócios com os ribeirinhos.

O auge da navegação de São Lourenço, de acordo com Costa, foi a década de 1930, quando a frota atingiu mais de cinqüenta lates. Desta forma, o período entre 1870 e 1945 foi aquele em que os barcos lourencianos buscaram as águas da Lagoa dos Patos e Lagoa Mirim, sendo os grandes anos da navegação de São Lourenço, cujas quilhas conquistaram todas as rotas das lagunas, trazendo riqueza e respeito para a cidade de São Lourenço do Sul (Costa, 1999: 55).

Sendo assim, a prática dos lates em São Lourenço do Sul estendeu-se até aproximadamente a década de 30 do século XX. No entanto, em outras localidades, o mesmo período marca o 
início da decadência desta antiga forma de escoamento. A fundação do DAER ${ }^{5}$ em 1938 pela política rodoviária estadual foi o marco da derrocada dos lates na região (Copstein, 1992: 88). No entanto, em São Lourenço do Sul, sua utilização pode ser acompanhada, em quantidades muito inferiores, até pelos menos a década de 1970 com o escoamento da safra do arroz.No entanto, sofriam também com a competição das vias férreas e com as baixas tarifas cedidas para esta atividade (Id. Ib.).

A atividade dos lates no porto articulou também a cidade com as demais localidades portuárias. Desse modo, pode-se dizer que as características peculiares da circulação de pessoas, mercadorias e barcos, ligando portos e cidades, configuram uma extensão do fenômeno urbano. Em certa medida, a organização espacial da cidade e os vestígios a beira-rio refletem ainda a organização daquela sociedade.Neste processo, era pelo rio São Lourenço que os produtos coloniais, tais como lenha, feijão, batata, arroz, milho, manteiga, frutas, galinhas, porcos, carvão eram exportados. Com o advento da colônia, o fluxo e a diversidade de produtos e pessoas acrescentaram multiplicidade da paisagem privilegiada neste estudo.

\section{Espaço e mémoria. 0 silêncio da paisagem}

Para melhor compreensão desta discussão, é preciso que se faça a distinção entre espaço e paisagem. Sendo assim, "a palavra espaço tem o seu uso associado indiscriminadamente a diferentes escalas, global, continental, regional, da cidade, do bairro, da rua, da casa e de um cômodo no seu interior" (Corrêa, 1995: 15). Pode-se compreender o espaço como as percepções que cada indivíduo tem sobre os lugares que passa, convive ou habita. Considerando-o como uma abstração, cada indivíduo possui sua percepção de acordo com elementos que experimenta. Nesse sentido,não há delimitações para este espaço. Ele é percebido, sentido e apropriado.

De acordo com Orser, no seu sentido mais amplo, espaço refere-se à realidade física onde as coisas não estão localizadas. O espaço é irrefutavelmente ligado ao lugar,onde algo está localizado. Espaço, embora mensurável, pode ser uma abstração ligada a uma rede invisível, cujas percepções abrangem diferentes noções do espaço (Orser, 1996a: 136).

Já a paisagem pode ser entendida como o "conjunto de formas que, num dado momento, exprimem as heranças que representam as sucessivas relações localizadas entre homem e natureza. O espaço são essas formas mais a vida que os anima" (Santos, 2006: 66).

É fundamental abordar paisagem como a percepção dos elementos capazes de revelar o modo pelo qual foi produzida, possibilitando assim uma discussão de sua evolução e produção (Vieira, 2003: 4). Esses elementos que compõem um passado e que nela se entrelaçam podem ser tomados como instrumentos de trabalho, compondo um palimpsesto de memória viva (Santos, 2006: 69). 
É imprescindível destacar que os vestígios deixados para o estudo da zona a beira-rio constituem-se na existência física dos prédios comerciais que restaram da época dos iates mercantes, fotografias de acervos pessoais de diversas famílias que contribuíram com o estudo e dos relatos de poucas pessoas que vivenciaram essa época e que ainda são capazes de dar vida e movimento ao local.

Sendo assim, consideramos o espaço portuário da cidade de São Lourenço do Sul como o centro das relações sociais, comerciais, políticas e de trabalho, que durante o final no século XIX e meados do século XX constituiu-se como o palco dessas diversas interações. $O$ rio foi moldando as casas ribeirinhas de acordo com suas curvas. Em seu próprio curso eram feitos os compartimentos para carga e descarga de mercadorias. Cada late que entrava no canal já sabia onde era o local de atracar. Essas práticas abrem perspectivas para que se proceda uma leitura dos espaços urbanos, destacando assim as formas como foram preservados os testemunhos dos modos de vida e das práticas cotidianas que caracterizaram o espaço a beira-rio.

As interações entre as pessoas que coexistem na paisagem física compõem a estrutura sóciohistórica. Sendo assim, a definição da paisagem descrita por Orser (1996a) permite a reflexão para o estudo do espaço portuário, antiga zona comercial da cidade de São Lourenço do Sul. Esta paisagem natural ordenou e estruturou a ocupação e a utilização do espaço à ribeira e tal como aborda Torres (2010:75), são nas práticas e lugares rotineiros da vida cotidiana que se processa a trama social, "um marinheiro experiente, um capitão severo, um carpinteiro habilidoso, um caixeiro bom de negócio, etc".

Já Bender (2002) evidencia que as paisagens não são apenas cenários, mas conflitos profundos. Elas não são somente vistas, mas vivenciadas, o que nos permite considerar a forma como designamos significados aos lugares e como os relacionamos com nossas memórias e histórias, permitindo a criação de sentido e pertencimento.

Um conceito de "paisagem" invariavelmente inclui um conceito de "fronteira", pois as paisagens devem terminar em algum lugar no espaço (Orser, 1996a: 139). Quando a paisagem é pensada como composta por estruturas derivadas das relações que os indivíduos estabelecem entre si e com o meio, as fronteiras assumem esse caráter de flexibilidade e de difícil caracterização. Sendo assim, utilizando o sentido de flexibilidade de Orser, as fronteiras podem ser percebidas no espaço a beira-rio. Os colonos vindos do interior em direção ao porto trazem suas carroças carregadas de produtos coloniais. De outros portos, aparecem os lates mercantes carregados de mercadorias ou prestes a carregá-los. Os comerciantes que permaneciam no limiar de receber produtos coloniais e escoar o excedente dependiam tanto dos colonos quanto dos navegadores. E a sociedade em geral, que utilizavam o espaço a fim de consumir, de se relacionar, de se divertir e etc.

Se consideramos que paisagem cultural pode se tornar maior para incluir todos os aspectos do espaço cultural definido, isso inclui a arquitetura, a organização da cidade, as redes de comunicação regionais, campos e terrenos baldios. A paisagem não é apenas um contexto físico que ajuda a constituir as relações sociais, mas é um contexto significativo também (Hood, 1996:123). 
O contexto histórico da paisagem do rio São Lourenço denota, entre o final do século XIX e meados do século XX, uma mudança significativa nas relações sociais, econômicas, políticas e de trabalho. Neste contexto, as casas ribeirinhas acompanham as curvas do rio, seja para moradia ou para o comércio. A partir da crescente demanda regional, a paisagem a beira-rio passa a ser transformado e re-configurado diante dessa nova ordenação social, espacial e econômica. Uma paisagem múltipla de vetores e significados era composta de mastros, velas, embarcações, carroças, pessoas, casas, rio, etc.

O rio passa a interagir com a sociedade como uma extensão do fenômeno social e econômico. Estes espaços são acessórios criados pela atividade humana e não são necessariamente propositais ou projetados, mas podem fornecer informações úteis para aqueles que desejam estudar a analogia entre relações sociais e a cultura material (Hood, 1996: 122).

Paisagens nunca permanecem estáticas, pois os sentimentos e o envolvimento com lugar estão sempre em criação. Também não podem ser situadas somente no presente por conterem e serem referenciadas no que ocorreu antes. Alguns autores a denominam como "palimpsesto", o que significa que atividades passadas deixam suas assinaturas sobre a terra. Isto sugere que elementos do passado são simplesmente deixados "no lugar" (Bender, 2002: 137).

No sentido de Tilley, as paisagens são contestadas, trabalhadas e re-trabalhadas por pessoas de acordo com as circunstâncias particulares, sociais e políticas. Como tal, estão sempre em processo. Paisagens são estruturas de sentimento e ativamente retrabalhadas, interpretadas e compreendidas em relação às diferenças, formas da memória social, biografias e consubstanciadas numa multiplicidade de formas (Tilley, 2006: 7-8).

Para os navegadores, tripulantes e mestres, a noção do espaço se relacionava às necessidades da navegação através das redes que conectavam o circuito comercial fluvial das Lagoas Patos e Mirim. Tal como afirma Ecléa Bosi (2003), a recuperação da dimensão humana no espaço é um dos problemas políticos mais urgentes. O tempo de vida de um grupo está relacionado à morfologia da cidade, e quando há uma desconexão deste elo, causa um grau intolerável de desenraizamento.

Outra referência importante sobre o espaço dos lates é a respeito do reparo dos mesmos que era feito anualmente. Entre dezembro e janeiro os barcos paravam suas atividades por aproximadamente um mês e se instalavam nos Estaleiros, onde "os carpinteiros da ribeira e os calafates $^{6}$ executavam os trabalhos especializados" (Copstein, 1992: 70). Além dos trabalhos de reparos e calafetagem havia também o trabalho de manutenção das velas dos lates. Esta tarefa, totalmente especializada, era feita apenas por duas pessoas em São Lourenço, de acordo com os relatos orais: o senhor Juvenal Jorge Martins e seu filho Lourenço Martins. Aos oitenta e sete anoso senhor Lourenço ainda lembrava sobre a atividade exercida, como aprendeu e contou que ainda guardava seus instrumentos de trabalho.

6 Trabalho que consistia em vedar com estopa alcatroada as juntas dos navios. 
As agulhas eram vendidas na casa Helmse Nickhorn e eram importadas da Inglaterra. O senhor Lourenço ainda possuia três agulhas de numeração e funcionalidades diferentes. Possuia ainda um pedaço de lona que era utilizada no reparo das velas, uma faca muito pequena que pertenceu ao seu avô e que ele utilizava para cortar as linhas, o repuxo, que servia como dedal e o caveirão, instrumento pontiagudo de madeira, que ajudava a desmanchar os nós das cordas da embarcação.

O entrevistado relatou que após o trabalho de confecção das velas, as mesmas eram colocadas pelos tripulantes do barco, ao contrário do que se possa imaginar de que era ele quem as colocasse. Mostrou também as agulhas que eram utilizadas de acordo com suas funções e após relatar o serviço praticado, relembra do esforço de realizar a tarefa. Comentando que eram os marinheiros a colocar as velas no barco, recupera o esforço em movimentar o pano, em enfiar as agulhas, sentado em um pequeno banco. Na tarefa de entralhar o pano ${ }^{7}$, expressão própria do jargão de trabalho, o manuseio com as agulhas era de fundamental importância, sendo que apenas a experiência do ofício podia garantir um bom resultado e aproveitamento de material.

Outro aspecto relacionado às atividades dos lates é o que se refere ao conhecimento do rio e suas características como, por exemplo, os chamados "bancos de areia", depósitos de areia que se deslocavam de acordo com as correntes dentro da Lagoa e que eram um obstáculo aos navegadores. Para os que vinham de São Lourenço, a maior dificuldade estava na llha da Feitoria $^{8}$. Os equipamentos utilizados para navegação limitavam-se a bússolas, barômetro e prumo. Este último servia para indicar se o mestre estava dentro do canal ou fora dele.

Desse conhecimento, essencialmente empírico, ressalta que o marinheiro devia conhecer tudo, saber rumos, horários: "botavam-se os rumos e não precisava de nada, de GPS, não precisava nada. Isso é a prática!" ${ }^{9}$ Essa percepção das condições ambientai será fundamental para se projetar o tempo de trajeto entre um local e outro, sobretudo com uma embarcação como os lates que se movimentavam pela ação do vento. "Barco à vela tu não sabe, daqui tu sai o vento muda ali e tu não chega. Com vento normal tusaía de manhã e chegava a tarde em Rio Grande, mas se o vento calmou, ah! Já não chega", tal como afirma o entrevistado. É dessa experiência, dessa certa sensibilidade desenvolvida em face ao ambiente e do conhecimento da própria embarcação, que se estabeleciam os rumos a tomar e as precauções para evitar acidentes e naufrágios. Os relatos dão conta dos temores que envolviam a Lagoa dos Patos.

O saber-fazer que caracteriza esses ofícios ligados aos barcos e ao mar pode ser abordado enquamto atividades que não passam por uma formação profissional estritamente técnica, mas sim a capacidade de compreender seu ofício como uma extensão de sua experiência, de fazer escolhas de acordo com seus parâmetros pessoais. É a experiência que confere a capacidade de prever, de escolher e aferir seus próprios limites, experiência essa que não está necessariamente vinculada ao aprendizado técnico.

7Unir a vela a uma corda contínua mediante costuras.

8 A referida Ilha da Feitoria pertence à planície costeira, localiza-se a sudoeste da Lagoa dos Patos a 3 metros do nível do mar. 9Entrevista com o senhor Orocildo de Moraes. 21/04/2008. 
Se a aquisição de um saber-fazer não depende do aprendizado técnico, nem mesmo da repetição pura e simples desses gestos, é preciso atribuir isso a certos elementos que atuam em conjunto. No que se refere aos ofícios náuticos, esses saberes estão associados com habilidades como a destreza em manejar a agulha na costura e remendo de panos, à identificação de correntes de vento e sua orientação, ao reconhecimento de alterações na superfície da água do rio. É sempre difícil aos pesquisadores compreender esses fenômenos, sobretudo em razão de uma descrição sempre minimalista da origem e transmissão de um saber-fazer (Rasse, 1991).

Os tripulantes dos lates obedeciam a uma hierarquia disposta na seguinte ordem: mestre, marinheiro, moço de convés e cozinheiro. De acordo com os relatos obtidos, a aprendizagem profissional se fazia na prática e um hábito comum era que os pais, que já eram profissionais do ramo, iniciassem seus filhos na profissão. Porém nada impedia a entrada de estranhos na tripulação de acordo com as necessidades da embarcação e do comércio.

O trabalho relativo às embarcações era, via de regra, mantido na informalidade sem que houvesse um contrato selado entre as Casas de comércio e os trabalhadores responsáveis pelo transporte aquático. As entrevistas referentes ao período anterior a implantação da legislação trabalhista no Brasil, que ocorre em $1943^{10}$, falam de condições muito duras de trabalho, com jornadas de 12 horas sem nenhuma garantia salarial, benefícios e obrigações por parte do contratante. Considerando que essas embarcações operavam em águas da Lagoa dos Patos e Lagoa Mirim, era sobretudo durante o período do inverno que, tal como falam os entrevistados, mais acidentes ocorriam e as condições atmosféricas geravam grande desconforto pelo frio e umidade.

Atualmente a paisagem a beira-rio demonstra sinais do abandono, pois não apenas os lates perderam sua utilidade e funcionalidade, como também as casas de comércio. Algumas dessas antigas casas de comércio estão em estado de ruína, outras se mantiveram razoavelmente conservadas, mas apenas na fachada e atualmente são utilizadas para outros fins. Essa que era uma região muito marcada pelo barulho e atividade comercial hoje é vista como marginal dentro do contexto urbano, esvaziada de toda sua atividade anterior.

O rio, em alguns pontos de sua extensão está coberto por vegetação tal como as água-pé ${ }^{11}$ com exceção da entrada da barra que é local de atracadouro de barcos pesqueiros, barcos particulares e escunas de passeio. Ao longo do rio a impressão é de que ele sempre esteve em seu estado natural, sem rastros do passado, tornado impossível a imaginação de que ali houvera o trânsito constante de embarcações.

10 A Consolidação das Leis do Trabalho (CLT) surgiu pelo Decreto-Lei no 5.452, de 1 de maio de 1943, sancionada pelo então presidente Getúlio Vargas, cujo objetivo foi instaurar uma legislação trabalhista que atendesse à necessidade de proteção do trabalhador, dentro de um contexto de "estado regulamentador". Sendo assim, regulamenta as relações trabalhistas, tanto do trabalho urbano quanto do rural. Desde então continua sendo o principal instrumento para regulamentar as relações de trabalho e proteger os trabalhadores.

11 Aguapé é a denominação popular de algumas espécies de plantas aquáticas. São flutuantes e tem preferência por rios de fluxo lento ou lagoas de água doce. 
A narrativa oficial sobre a história de São Lourenço do Sul não contempla as atividades do porto, relegando-o ao esquecimento. As alterações que ocorreram no sistema de transporte e comércio foram modificando também o cenário a beira-rio e as atividades que ali eram exercidas. $\mathrm{Na}$ fala dos entrevistados as mudanças ocorreram no sentido da desvalorização de saberes e ofícios que antes eram essenciais para a dinâmica econômica local. Essa desvalorização passa pela perda de autoridade associada a um saber que se originava na experiência, na vivência cotidiana dos sujeitos com o rio. "Hoje está tudo desvalorizado. Tudo, tudo. O marinheiro não é a mesma coisa. Tira a sabedoria do marinheiro" ${ }^{12}$.

Buscando encontrar as causas dessas mudanças,os entrevistados apontam para a introdução do transporte terrestre, feito através de caminhões, que atravessando a zona rural, possibilitaram um esvaziamento dos barcos como transporte de mercadorias. As transformações no sistema produtivo também foram fundamentais para o que esses entrevistados caracterizam como enfraquecimento da região. De uma economia baseada em pequenas propriedades relativas à unidades familiares e caracterizada por policulturas e pequena criação doméstica de animais como aves e porcos, a introdução de monocultura do fumo nos anos 1970 veio alterar bruscamente a paisagem e os modos de viver.

Com a implementação dos sistemas produzidos baseados na agricultura moderna como a prática da agricultura integrada ao fumo pelas indústrias fumageiras e a introdução da soja, a chegada da extensão rural e da pesquisa agropecuária determinaram modificações substanciais em grande parte dos sistemas produtivos adotados nos estabelecimentos rurais. No entanto, na década de 1980, o ritmo do crescimento econômico da agricultura diminui. Dificuldades de mercado levam ao declínio de batata e da soja, o que é compensado apenas em parte pela expansão da produção de fumo (Lima, 2006: 97-98).

Neste momento, a crise do sistema colonial imigrante começa a tornar-se evidente, uma vez que os colonos não mais dispunham de terras virgens para plantar. Durante muito tempo o sistema de queimada prosperou devido à relativa disponibilidade de terras dos agricultores. $\mathrm{Na}$ medida em que essas terras iam sendo utilizadas na produção agrícola, iam também acabando as áreas disponíveis de floresta, ricas em fertilidade natural (Lima, 2006: 93).

Desta forma, os trabalhadores do meio rural buscaram alternativas diante de uma sucessão de mudanças que influenciaram para que a atividade agrícola perdesse espaço e passasse a não se constituir mais como a única opção para a manutenção das famílias no campo. O termo pluriatividade, sugerido por Anjos (2003), designa o conjunto de atividades desenvolvidas pelos integrantes da família rural.

A pluriatividade é, sobretudo, uma alternativa para incentivar a manutenção dos agricultores familiares no campo já que estes viram refletidas as transformações na agricultura de forma direta na sua produção, pois, em grande parte das vezes, se torna irrealizável a adaptação destas propriedades familiares à agricultura mecanizada e intensiva (Anjos, 2003). Em consequência disso, nas últimas décadas o turismo rural tornou-se uma alternativa capaz de 
promover o reerguimento de propriedades atingidas pelo processo excludente da industrialização (Santos e Klumb, 2008).

Neste contexto de transformações políticas e econômicas, não somente as atividades inerentes à produção rural foram atingidas, mas todo um sistema que se interrelacionava com as atividades rurais. Neste caso, as atividades portuárias e as casas de comércio situadas a beira-rio perderam sua funcionalidade diante da nova ordem econômica e social.

\section{Políticas públicas acerca do patrimônio cultural da cidade}

A partir de 2005, a administração municipal de São Lourenço do Sul, passou a desenvolver ações público-privadas no intuito de difundir e valorizar a cultura dos imigrantes alemãespomeranos na cidade e região. Tal iniciativa, atrelada principalmente ao turismo, surgiu como uma alternativa econômica para os descendentes de imigrantes moradores na zona rural do município, já que a produção da colônia estava em franco declínio.

Desta forma, com o passar dos anos, este projeto foi ganhando cada vez mais espaço e incorporações. Neste processo, embora o discurso oficial não admita tal postura, elementos que não estão associados à imigração européia não ganham espaço evalorização. Exemplo claro disso são as ruínas e a marginalização na zona do antigo porto.

Nesse sentido, é possível localizar duas extremidades da sociedade atual de São Lourenço. Ao mesmo tempo em que ela exerce um esforço de memória, e busca na história os elementos identitários de coesão social, ela se adapta a novos marcos sociais devido às outras memórias terem se esvanecido no âmbito da coletividade. De acordo com Candau, quando os marcos se destroem ou se modificam é preciso estudar os modos de memorização, pois estes modos e seus atores se transformam para adaptarem-se aos novos marcos sociais instaurados (Candau, 2002: 66).

Essa constituição da memória pública em torno dos elementos ligados à colonização pomerana, enquadra-se tipicamente nos processos de reconstrução identitária. Políticas públicas relativas à valorização da memória e dos costumes pomeranos, articuladas principalmente a partir de ações ligadas ao turismo, retrabalham símbolos culturais em favor do esforço mencionado. Festejos, rotas turísticas, dia do colono e a construção da embarcação mítica da vinda dos colonos pomeranos, são algumas das estratégias que atualmente tem direcionado a construção da memória pública. As relações entre a memória pública e os testemunhos individuais e materiais devem ser observados com olhos críticos, principalmente nos processos de reconstrução identitária.

Entretanto, história e memória também são constituídas por detalhes e personagens mais ou menos difusos, cuja participação nos processos sócio-históricos é constantemente obliterada nos esforços oficiais de enquadramento da memória. Verificamos que a perda dos suportes biográficos e materiais desse período, associada àseleção efetuada pela memória pública em prol da herança cultural pomerana, tem resultado numa desapropriação dos elementos 
constitutivos do patrimônio histórico da cidade, condicionando a percepção da história e o sentido coletivo de pertencimento.

Sendo assim, segundo Cazzetta (1991: 192) "o passado tem sido transformado num produto chamado patrimônio e este patrimônio tem sido empacotado num embrulho chamado interpretação". Se a interpretação surge como agente reguladora de determinação do patrimônio, ela está intimamente ligada às disputas de poder da memória social de determinada sociedade, reivindicações identitárias e principalmente interesses políticos fomentados pelo turismo.

A ação pública em prol da cidadania, e a sua associação com o turismo, deve ser consolidada nas denominadas políticas públicas, deixando claro aos cidadãos os princípios norteadores e ações decorrentes para viabilizar este ideário. No contexto da política cultural, políticas públicas seriam as intervenções realizadas pelo poder público, instituições civis, entidades privadas e grupos comunitários, com o objetivo de atender à população nas suas necessidades materiais e simbólicas, garantindo-lhes acesso às mesmas para que seja alcançada maior e melhor qualidade de vida, não só para os grupos hegemônicos mas também, e em especial, para os excluídos por razões econômicas, sociais e culturais, etárias ou de gênero, dentro do respeito do direito à diferença (Gastal e Moesch, 2007: 39-40).

As políticas públicas são um conjunto de ações que visam determinados objetivos, e podem se desenvolver tanto no plano da sua implementação efetiva quanto no nível do discurso através de sua simples formulação. Isto significa que, nestes casos, o plano das intenções é importante, pois ele tem muito a revelar sobre o pensamento corrente a respeito de um determinado campo de interesse da sociedade (Sant'anna, 1995).

\section{Conclusão}

Atualmente, o discurso encontrado sobre a cidade são memórias que foram construídas em relação ao seu passado. Memórias que são comemoradas, lembradas e que produzem e reproduzem discursos até o ponto de virarem símbolo de uma cidade, cuja diversidade está espalhada na sociedade através de seus arquétipos e nos vestígios que não convergem com o discurso atual. Sendo assim, estruturas relacionadas a outras diretrizes e que também remontam à história do município, juntamente com a pluralidade de atividades exercidas são relegadas destas ações políticas de salvaguarda do que foi determinado como patrimônio de São Lourenço do Sul. O desafio é, como cidadãos, professores e acadêmicos, estarmos atentos às facetas utilizadas para que opatrimônio mostre e ao mesmo tempo oculte elementos conexos da mesma sociedade e as consequências disso no presente e futuro.

\section{Referência}

ANJOS, Flávio Sacco dos. Agricultura Familiar, Pluriatividade e desenvolvimento rural no sul do Brasil. Pelotas: EGUFPEL, 2003. 
ABREU, EgonZiebell de. Aconteceu no Sobrado. Contos da história de um povo da Lagoa dos Patos. Esteio: Pabreu Design\& Comunicação, Ed. do autor, 2001.

BENDER, Barbara. LandscapeandPolitics. In: The Material Culture Reader. Edited by Victor Buchli. Berg Publitions, Oxford, New York: 2002.

BOSI, Ecléa. O tempo vivo da memória: ensaios de Psicologia Social. Ateliê, 2003.

CALDAS, Pedro Henrique. Boqueirão e São Lourenço - Relatos da Monarquia à República. 2a Ed. São Lourenço do Sul: Survai Edições, 2009.

CANDAU, Joël. Antropología de la memoria. Buenos Aires: Nueva Visión, 2002.

CAZZETTA, Miriam. In: Anais do I Congresso Latino-Americano sobre a cultura arquitetônica e urbanística. Porto Alegre: PMPA/SMC, 1991: 190-196.

COARACY, Vivaldo. A colônia de São Lourenço e seu fundador Jacob Rheingantz. São Paulo, 1957.

COPSTEIN, Raphael. Iates na navegação do rio Grande do Sul. Revista do IHGRGS. Porto Alegre, 1992. $N^{\circ} 128$.

CORRÊA, Roberto L. Espaço, um conceito-chave da Geografia. In: CASTRO, I. E., CORREA, R. L. e GOMES, P. C. C. (orgs.). Geografia: Conceitos e Temas. Rio de Janeiro: Bertrand Brasil, 1995, p. 15-47.

COSTA, Jairo Scholl da. Navegadores da Lagoa dos Patos. A saga náutica de São Lourenço do Sul. São Lourenço do Sul: Hofstätter, 1999.

GASTAL, Susana; MOESCH, Marutschka Martini. Turismo, políticas públicas e cidadania. São Paulo: Aleph, 2007. (Coleção ABC do Turismo).

HOOD, J. Edward. Social Relations and the Cultural Landscape. In: Yamin, Rebecca and Karen BeschererMetheny (Eds). Landscape Archaeology: Reading and Interpreting the American Historical Landscape. The University of Tennesse Press. Knoxville: 1996.

IEPSEN, Eduardo. Jacob Rheingantz e a colônia de São Lourenço: da descontrução de um mito à reconstrução de uma história. Dissertação de mestrado. Programa de pós-graduação em História. Unisinos/RS. São Leopoldo, 2008.

LIMA, Maria Imaculada Fonseca. Paisagem. Terroir e sistemas agrários: um estudo em São Lourenço do Sul. Dissertação de Mestrado em Desenvolvimento Rural. Universidade Federal Do Rio Grande do Sul/UFRGS. Porto Alegre, 2006.

ORSER, Charles E. A Historical Archaeology of the Modern World. New York, Plenum Press: 1996a.

RASSE, Paul, 1991, "La cité aromatique”, Terrain, numero-16 - Savoir-faire , [En ligne], mis en ligne le 24 juillet 2007. http://terrain.revues.org/index2993.html. Consulté le 01 novembre 2009. 
Políticas da Memória e do Esquecimento: O Patrimônio do Porto de São Lourenço do Sul/RS e a sua Importância na Constituição da Cidade.

SANT'ANNA, Marcia. Da cidade-monumento à cidade-documento: a trajetória da norma de preservação de áreas urbanas no Brasil (1937-1990). Salvador: UFBA, 1995. Dissertação (Mestrado em Arquitetura e Urbanismo), Faculdade de Arquitetura, Universidade Federal da Bahia, 1995. p.37.

SANTOS, Nara Nilcéia da Silva e KLUMB, Guilherme Peglow. Caminho Pomerano: O turismo rural baseado no patrimônio cultural e a Pluriatividade. GT "Turismo e Patrimônio Cultural" do V Seminário de Pesquisa em Turismo do MERCOSUL - Caxias do Sul junho de 2008.

SANTOS, Milton. A Natureza do Espaço: Técnica e Tempo, Razão e Emoção/Milton Santos. - 4. ed. São Paulo: Editora da Universidade de São Paulo, 2006.

SAVIANI FILHO, Hermógenes. O processo de colonização no Rio Grande do Sul: o caso de São Leopoldo no século XIX. Programa de pós-graduação em Economia. Universidade Federal do Rio Grande do Sul. Porto Alegre, 2008.

SPALDING, Walter. Construtores do Rio Grande. Volume III. Editora: Sulina RS: 1974.

TILLEY, Christopher. Introduction: Identity, Place, Landscape and Heritage. In: Journal of Material Culture. Vol. 11(1/2): 7-32. Copyright @ 2006 SAGE Publications (London, Thousand Oaks, CA and New Delhi).

TORRES, Rodrigo de Oliveira. “... e a modernidade veio a bordo: Arqueologia histórica do espaço marítimo oitocentista na cidade do Rio Grande/RS". 2010. 94f. Dissertação (Mestrado) - Programa de Pós-Graduação em Memória Social e Patrimônio Cultural. Universidade Federal de Pelotas, Pelotas, RS.

VIEIRA, Sidney Gonçalves. Breves notas acerca da paisagem urbana. In: O centro vive. Tese de doutorado. Programa de pós-graduação em Geografia UNESP/SP. Rio Claro, 2003. 